\title{
RACISMO E VIOLÊNCIA CONTRA QUILOMBOS NO BRASIL
}

\author{
Eduardo F. de Araújo \\ Universidade Federal da Paraíba (UFPB) \\ Givânia Maria da Silva \\ Universidade de Brasília (UnB)
}

\begin{abstract}
RESUMO
No ano de 2018 a Coordenação Nacional de Articulação das Comunidades Negras Rurais Quilombolas, a Terra de Direitos, a Associação de Advogados de Trabalhadores Rurais da Bahia e Coletivo Joãozinho do Mangal - Assessoria Jurídica Popular lançaram o relatório Racismo e Violência contra Quilombos no Brasil com a finalidade expor em âmbito nacional e internacional as violações de direitos humanos perpetradas contra quilombolas no Brasil. Além do viés de denúncia, o relatório contribui para compreensão das formas de (re)existências através das mobilizações políticas e jurídicas por direitos. O relatório compila memórias e lutas sociais, jurídicas, políticas e culturais desenvolvidas por lideranças quilombolas e das assessorias jurídicas. A identidade a ancestralidade e as territorialidade compõe uma circularidade de saberes-fazeres que demonstram a atualidade das reivindicações dos quilombos frente à ordem neocolonial, neoliberal e racista da sociedade e do Estado brasileiro. Em 2003 foi promulgado o Decreto 4.887, com a finalidade de regulamentar os direitos constitucionais (Constituição Federal da República Federativa do Brasil de 1988) ao território. O Decreto foi atacado pela frente ruralista em 2004 perante o Supremo Tribunal Federal, o julgamento durou 14 anos. Em 2018 o STF acatou a tese de constitucionalidade defendida pelos quilombolas.
\end{abstract}

Palavras-Chaves: Racismos. Direitos Humanos. Assessoria Jurídica Popular.

\section{RACISM AND VIOLENCE AGAINST QUILOMBOS IN BRAZIL}

\begin{abstract}
The National Coordination of Articulation of Quilombola Rural Black Communities, Land of Rights, the Association of Rural Workers' Lawyers of Bahia and Collective Joãozinho do Mangal Legal Advice, in 2018, launched the report Racism and Violence against Quilombos in Brazil with the national and international violations of human rights carried out against quilombolas in Brazil. In addition to the reporting bias, the report contributes to understanding the forms of (re) existence through political and legal mobilizations by rights. The report compiles social, legal, political and cultural memories and struggles developed by quilombola leaders and legal advisors. The identities, ancestralities and territorialities make up a circularity of know-how that demonstrate the relevance of the quilombos' claims to the neocolonial, neoliberal and racist order of society and the Brazilian State. In 2003, Decree 4.887 was promulgated, with the purpose of regulating the constitutional (CRFB / 1988) rights to the territory. The Decree was attacked by the ruralist in 2004 at the Federal Supreme Court, the trial lasted 14 years. In 2018 the STF complied with the thesis of constitutionality defended by the quilombolas.
\end{abstract}

Keywords: Racism. Human rights. Legal advice for social and popular movements. 


\section{BREVE INTRODUÇÃO SOBRE OS QUILOMBOS NO BRASIL}

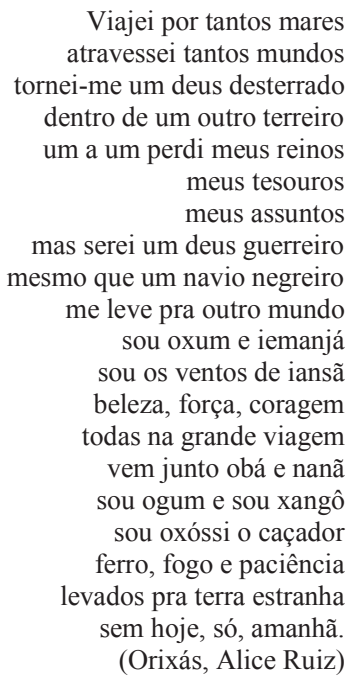

O lapso temporal compreendido entre os séculos XIV-XIX registra que cerca de dez milhões de africanos(as) foram sequestrados de África e trazidos(as) para as Américas, o Brasil teria recebido por volta de três milhões e meio destas(es) escravizadas(os). O colonialismo, caracterizado pelas violências (físicas, psicológicas e/ou simbólicas) e os racismos atravessam os últimos 500 anos na sociedade brasileira, tanto em um plano macrossocial quanto nas micro relações do cotidiano.

O historiador Flávio Gomes (2003: 447) aponta que o entendimento sobre a colonização do Brasil pressupõe a utilização de duas chaves interpretativas que aparentemente são concorrentes, mas se articulam, formando um passado estanque, um presente amorfo e um futuro insólito - são elas o essencialismo ou idealismo sobre a formação das resistências por um lado, e a naturalização da violência praticada pelos colonizadores de outro.

O autor propõe que se perceba o processo de colonização e escravidão não apenas pela natureza bélica, mas (talvez sobretudo) no estabelecimento de padrões culturais, econômicos, científicos, jurídicos e políticos que forjaram a sociedade brasileira. $\mathrm{O}$ uso do essencialismo ou da naturalização produzem memórias que congelam outras possibilidades de narrativas submersas e ao mesmo tempo escondem reações ao status quo. Em relação aos quilombos silenciam "experiências históricas, envolvendo trocas culturais, dominação, conflitos, protestos e confrontos que uniram, inventando, Europas, Américas e Áfricas” (Gomes 2005).

No ocidente europeu do norte, se um espectro rondava a Europa em 1888, antes, no Haiti em $1522^{1}$, no Brasil em $1575^{2}$ e em $1605^{3}$ eram nítidas as mobilizações e as práticas insurgentes

\footnotetext{
${ }^{1}$ No ano de 1522 ocorreu o primeiro levante de escravizados em São Domingos - posteriormente, Haiti, primeiro país a abolir a escravidão.
} 
contra o sistema colonial escravista, sendo o Quilombo de Palmares uma das referências destas rebeliões no Brasil. Diversas pesquisas e autores (Arruti 2006; Gomes 2005; Lopes 1998) analisaram a experiência de resistência dos povos escravizados, mais especificamente na região nordeste do Brasil e sua relação com o Quilombo de Palmares. Pesquisas apontam que o início de Palmares é no final do Século XVI, na região da Serra da Barriga (atual estado de Alagoas), e as batalhas contra as tentativas de invasão por parte dos holandeses e dos portugueses duraram cem anos.

A estimativa é que entre 15 mil e 30 mil pessoas formaram o contingente populacional do Quilombo de Palmares, composto por ex-escravizados, negras(os) libertas(os), pessoas brancas pobres e grupos de povos originários refugiados, ou seja, formaram uma sociedade quilombista, conforme aponta Abdias Nascimento (2002). Não existe idealização por parte das pesquisas, como se ali fora uma parte do continente africano dentro do Brasil, mas assumindo a perspectiva de que qualquer que seja o tipo de agrupamento societário - este formado por imposição da colonização constitui dinâmicas políticas, culturais, sociais, étnicas e outras que não foram previamente estabelecidas, mas, sim, confirmam a rebelião contra as violências do sistema escravista e o desejo de liberdade.

Várias foram as lideranças do Quilombo de Palmares, sendo em Zumbi (o último líder) e em Dandara (guerreira de Palmares) as representações icônicas das lutas por liberdade, pelo fim da escravidão e de resistência da população negra no Brasil ${ }^{4}$.

O quilombo ${ }^{5}$ no Brasil é uma dentre outras forma de enfretamentos contra a escravidão. A exploração e a opressão no período da colonização, porém, são aa primeiras a terem um dispositivo normativo a conceituá-las e uma previsão de punição exemplar em caso de localização identificada. De acordo com o Conselho Ultramarino, de 1740, em informe enviado ao Rei Dom João V de Portugal, o quilombo seria: "toda habitação de negros fugidos, que passem de cinco, em parte despovoada, ainda que não tenham ranchos levantados e nem se achem pilões nele”.

O historiador Décio Freitas (1982: 47) também demonstra que não houve apenas enfretamento bélico contra as insurreições da população negra, mas a intenção de impingir um

\footnotetext{
${ }^{2}$ Data de 1575 a primeira expedição com o intuito de reprimir a formação de mocambos e quilombos no Brasil, tal fato ocorrido na província da Bahia.

${ }^{3}$ Provável ano da consolidação do quilombo dos Palmares, o quilombo resistiu até o ano de 1710 quando os últimos residentes deixaram os povoados.

${ }^{4}$ Zumbi foi morto e decapitado no dia 20 de novembro de 1695. A cabeça de Zumbi foi exibida em praça pública durante dias, em Recife. No Brasil, o dia 20 de novembro (dia da Consciência Negra) é comemorado em contraposição ao dia 13 de maio de 1888, assinatura da Lei Áurea (abolição da escravidão) pela Princesa Isabel.

${ }^{5}$ Associação Brasileira de Antropologia (ABA) conceitua quilombo enquanto "uma herança cultural e material que lhes confere uma referência presencial no sentido de ser e pertencer a um lugar e a um grupo especifico." $<$ http//:www.abant.ogr.br>. Acesso em 12 de jan. de 2019.
} 
esquecimento destes conflitos com o intuito de forjar uma identidade "brasileira". Na transição entre o período escravista oficial (1530-1888) e começo da República Velha no Brasil (1889-1930), os quilombos se consolidaram, principalmente nas regiões de exploração da monocultura da canade-açúcar e da mineração (Ribeiro 1995).

Outras formas de organização comunitária se estabeleceram na história política e fundiária do Brasil, seja pela "interiorização dos libertos dentro de latifúndios, na compra e doação de terras" (Almeida 2002), nas alianças políticas com os abolicionistas, na participação em revoltas populares e na condição de abandonados nos centros urbanos. Flávio Gomes (2005) aponta a existência de diversas formas de organização destes quilombos, autodenominadas de terras de preto, mocambos, comunidades rurais, posseiros de engenho, lugares de preto e outros.

Os quilombos no Brasil através de suas dinâmicas políticas, sociais, raciais, culturais e econômicas, transcenderam a definição do Conselho Ultramarino de 1740 e aportam no termo quilombo dimensões de ancestralidade e territorialidade vinculadas (relacionais) ao continente africano, principalmente ao identificar no Bantu, língua da África Central (Centro-ocidental) a definição de Quilombo ou Kilombo enquanto acampamento, reunião de acampamentos ou união. Através da língua Iorubá a referência da palavra Quilombo é habitação (Lopes 1998).

Outros estudos mais avançados indicam os pertencimentos da expressão Quilombo a outras nações e idiomas dos Reinos de África, o que é natural pelo fato de que o processo de escravização forçou a relação de povos de África com hábitos, línguas, tradições e cosmovisões diversas, por vezes até inimigos entre si, mas que em um novo continente, diante das situações adversas, se autorganizaram.

O mais revelador é que o caráter racista e criminalizante constituído pela colonização portuguesa ao termo quilombo se transformou em sinônimo de liberdade, transgressão, revolta e identidade, sendo recuperado como termo forjado pela reunião de povos negros múltiplos e de luta antirracista.

A inclusão na Constituição Federal da República do Brasil de 1988 (CFRB 1988) dos artigos 215, 216 e do artigo 68 dos Atos das Disposições Transitórias Constitucionais (ADCT) são marcos normativos conquistados por duras batalhas travadas nos anos de 1970 e 1980 no Brasil. Neste momento de transição, de uma ditadura civil-militar para a democracia, o movimento negro denunciou o mito da falsa "democracia racial" no Brasil e resgatou a imagem de Zumbi dos Palmares enquanto símbolo antirracista e da afirmação pelo reconhecimento das pautas políticas no âmbito jurídico. Cabe apontar que, desde 1889 - começo da República no Brasil, um ano após a abolição da escravidão - , a CFRB 1988 é o primeiro instrumento legal a indicar os quilombos enquanto sujeitos de direitos. 
No ano de 2003 foi promulgado o Decreto $\mathrm{n}^{\mathrm{o}} 4.887 / 2003$, com a finalidade de dar operacionalidade ao artigo 68 da ADCT. Em 2004 o Partido da Frente Liberal (PFL, atualmente Democratas) e várias organizações representativas do agronegócio ingressaram com a Ação Direita de Inconstitucionalidade (ADI) $n^{\circ} 3239 / 2003$, para que o Decreto fosse declarado inconstitucional. O processo perdurou por 15 anos em trâmite no Supremo Tribunal Federal do Brasil (STF), sendo o Decreto declarado constitucional apenas em $2018^{6}$.

No embate político-jurídico foi rapidamente formado um arco de apoio ao partido ingressante da ação, formado pela Sociedade Rural Brasileira, a Associação Brasileira de Celulose e Papel, Confederação da Agricultura e Pecuária do Brasil (CNA) e a Confederação Nacional das Indústrias (CNI). A Advocacia Geral da União (AGU) se posicionou na ADI em defesa da constitucionalidade do Decreto, assim como a Procuradoria Geral da República. Da mesma forma, foi formado um campo de intervenção em defesa do Decreto, os Amici Curiae. E em prol das comunidades quilombolas reuniram-se o Estado do Pará (através do ITERPA - Instituto de Terras do Pará), associações quilombolas de diversos Estados, assim como diversas ONG's, entre elas, o Centro pelo Direito à Moradia contra despejo forçado (COHRE), a Justiça Global, a Terra de Direitos, a Sociedade Brasileira de Direito Público e outras.

No momento, a Coordenação Nacional de Articulação das Comunidades Negras Rurais Quilombolas (CONAQ) sinaliza a existência de um número superior a 6.000 quilombos no Brasil, enquanto o Estado brasileiro reconhece a existência de aproximadamente 3.500.

O Instituto de Colonização e Reforma Agrária (INCRA) trabalha em cerca de 3.000 quilombos em seus procedimentos de titulação e regularização fundiária. Conforme o Relatório Racismo e Violência contra quilombolas no Brasil (2018), entre 2003 e 2018 foram emitidos 116 títulos de titulação coletiva territorial aos quilombos.

Os números do orçamento federal apontam que os recursos destinados às indenizações para fins de titulação de territórios quilombolas entre os anos de 2010 e 2018 foram reduzidos de R\$ 54 milhões reais para pouco mais de $\mathrm{R} \$ 1$ milhão de reais.

Além dos dados e orçamentos, caso fôssemos realizar uma leitura da conjuntura políticajurídica, econômica e fiscal, assim como das alterações normativas, das modificações das estruturas institucionais no Governo Federal, do esvaziamento das políticas públicas (educação, saúde, participação, comunicação, cultura e agricultura familiar), dos cortes em programas sociais (bolsa família, programa mais médico e outros), da falta de representatividade política em instâncias de

\footnotetext{
${ }^{6}$ ADI no 3.239 contra o Decreto no 4.887/2003, que regulamenta o artigo 68 dos Atos das Disposições Constitucionais Transitórias (ADCT) da Constituição da República Federativa do Brasil (CRFB/1988). O Decreto prevê o reconhecimento, demarcação e titulação dos territórios quilombolas. Disponível em $<$ http//:www.stf.gov.br $>$. Acesso em :20 de mai. 2015.
} 
poder, acoplando os discursos do Poder Executivo, Legislativo e Judiciário nos últimos 03 anos, a síntese seria : o Racismo é estruturante no Brasil.

Os dados orçamentários, as informações (várias retiradas dos sites oficiais do governo federal) e notícias sobre a temática quilombola são alterados com frequência nos últimos meses (2019). A publicação da Medida Provisória no 870, de 01 janeiro de 2019, no dia da posse do Presidente Jair Bolsonaro, desestruturou as instituições e ministérios responsáveis pelas políticas públicas e até o momento (maio de 2019) as novas diretrizes não estão delineadas. O desafio atual é estabelecer uma rede de proteção local, nacional e internacional para atravessar um período de possíveis retrocessos. A defesa de direitos constitucionais e dos direitos humanos deve garantir o acesso cotidiano dos(as) quilombolas aos seus territórios.

Conforme demonstra o Relatório Racismo e Violência contra Quilombos no Brasil, além das violências físicas e psicológicas contra as pessoas, em várias regiões do Brasil, o que está em curso é a transição do modelo econômico neodesenvolvimentista (2000-2012), de combinações e compensações nos quais os conflito sócio-ambientais, econômicos, culturais, raciais e políticos eram mediados por algumas instâncias de poder no Governo federal, por vezes de maneira ineficaz, para a uma lógica predatória, neoextrativista, racista e neocolonial, onde a única plataforma é a radicalização do neoliberalismo. As instituições, principalmente do Governo federal, enxergam a natureza, os modos de vida comunitários e as diferenças interculturais como inimigas.

Por outro lado, o mesmo relatório aponta que é nos quilombos, através das mulheres quilombolas, que há uma comunicação efervescente que dialoga para si e para outros grupos (movimentos sociais, organizações não-governamentais e outros), apontam para suas ancestralidades e aproximam formas de uso do comum, da produção de conhecimentos e articulação com assessoria jurídica popular, assim como evidenciam, para o mundo exterior, uma consciência étnica-racial, cultural e territorial proveniente de uma "memória biocultural" (Toledo 2015), que através da circularidade das experiências se transmite oralmente indicando as resistências (reexistências) das lutas contra todas forma de racismos e violências, e o fazem pelo bem viver ${ }^{7}$.

\footnotetext{
7 Quilombolas (2014) - Documentário - Um filme de Ale Maciel Produção: Imagine Filmes www.imaginecultura.com.br - Sinopse: "O modelo de desenvolvimento com abordagem territorial que o movimento da Economia Solidária e a Senaes/MTE vem debatendo e construindo com a sociedade brasileira no último período, dialoga diretamente com os valores e princípios que o movimento quilombola e as comunidades tradicionais vêm praticando cotidianamente nos seus territórios seja através da sua cultura, seja pelo aspecto ambiental - protegendo as matas, os rios, a flora e a fauna. Dentro deste contexto, a Senaes/MTE, apoiou ao movimento quilombola, por meio do Confederação Nacional de Articulação das Comunidades Negras Rurais Quilombolas (CONAQ) e seu envolvimento na execução de um projeto com a finalidade de contribuir para a construção de uma política pública de economia solidária considerando a realidade quilombola. Tal iniciativa teve seu reconhecimento na medida em que Ronaldo Santos (liderança quilombola do RJ) afirmou que foi a "primeira vez que o movimento quilombola propôs e executou uma política pública em parceria com a Universidade Federal do Rio de Janeiro / Núcleo de Solidariedade Técnica (UFRJ/SOLTEC) e governo federal". Os resultados desta ação foram animadores. Eles atestam que o modelo
} 
José Maurício Arruti (2006: 107), ao realizar uma abordagem sobre as origens do movimento quilombola nos anos de 1990, aponta que é necessário o rompimento com as categorias tradicionais de análise dos movimentos sociais, visto que, as comunidades quilombolas constituem um campo de "re-semantização que integraliza a ideia étnico-camponesa".

\title{
1. A EXPERIÊNCIA DO RELATÓRIO RACISMO E VIOLÊNCIA CONTRA QUILOMBOLAS NO BRASIL (2018)
}

O Relatório Racismo e Violência contra Quilombos no Brasil, publicado pela Organização Não Governamental Terra de Direitos $^{8}$ e a Coordenação Nacional de Articulação das Comunidades Negras Rurais Quilombolas (CONAQ) ${ }^{9}$, foi elaborado em parceria com o Coletivo de Assessoria Jurídica Popular "Joãozinho de Mangal” e a Associação de Advogados(as) de Trabalhadores(as) Rurais da Bahia (AATR) com o objetivo de trazer o primeiro documento sistematizado e produzido por lideranças quilombolas da CONAQ em parceira com Assessoria Jurídica Popular (AJUP) sobre os racismos no Brasil e apontar formas de resistências para manutenção de direitos conquistados no Século XX - especialmente na CFRB 1988 - dentro de um contexto de enfretamentos contra retrocessos dos direitos humanos no Século XXI.

\begin{abstract}
"Os dados apresentados registram a ocorrência de 18 assassinatos de quilombolas em 2018, Números alartamentes não só pela frequência (mais de um assassinato por mês), como também pea extensão da violência (...) Para além do fato de o número de assassinatos ser preocupante, quilombolas sofreram processos múltiplos de biolencia em variadas intensidades : ameaças, torturas, prisões ilegais, despejos e negação sistemática de acesso a bens e serviços (...) parte permanente deste cenário o racismo religioso e institucional, bem como os conflitos em face de interesses políticos e econômicos transnacionais que se expandem sobre os territórios. As várias situações de violência mapeadas são reveladoras do estado de vulnerabilidade em que os quilombos se encontram atualmente, dando indicações do tipo e dos níveis dos ataques à vida, às relações culturais, às identidades, aos meios de subsistência e à posse sobre os territórios. (Relatório, 2018, p.18).
\end{abstract}

Todo esse trabalho de investigação foi pensado e construído por quilombolas, diversas instituições e pesquisadoras(es) estiveram engajadas(os) na elaboração do Relatório com ênfase no engajamento das mulheres quilombolas de diferentes regiões do país.

de desenvolvimento territorial sustentável e solidário envolve as comunidades respeitando a sua identidade, a sua própria forma de vida, os seus saberes, o jeito de fazer as coisas e viver feliz. A coerência no pensar e agir de toda equipe envolvida no apoio e realização do projeto para o etnodesenvolvimento no país possibilitou cumprir esta importante tarefa que certamente não se encerra aqui. Vida longa para o etnodesenvolvimento e as comunidades tradicionais que preservam e constroem outro modelo de desenvolvimento para o Brasil. Equipe SENAES/"em". Disponível em <https:/www.youtube.com/watch?v=DylaGylpZY4\&feature=share>. Acesso em 30 mai.2019.

${ }^{8}$ Terra de Direitos. Disponível em <https://terradedireitos.org.br/>. Acesso em: 30 de mai. 2019.

9 Coordenação Nacional de Articulação das Comunidades Negras Rurais Quilombolas. Disponível em $<$ http://conaq.org.br/>. Acesso em: 30 mai. 2019 
O Relatório é uma denúncia, mas também um instrumento de pesquisa para aferição dos processos de criminalização contra lideranças, dos ataques contra os quilombos (homicídios e outros), das ameaças físicas e psicológicas (individuais e coletivas), dos atos violentos por ação e omissão do Estado, ao mesmo tempo, que demonstra a defesa permanente das quilombolas do seus territórios enfrentando os racismos (institucional, estrutural e ambiental), os discursos de ódio, de intolerância e discriminação na sociedade brasileira e nas instituições do Estado.

\footnotetext{
"O racismo é elemento estruturante dessas violências: seja o racismo institucional - presente na historia de negação do acesso à terra ao povo negro escravizado e seus descendentes -, seja o racismo epistêmico e econômico que considera a vida negra descartável e, portanto, não humana. A elite econômica e política, em sua maioria comandada por homens brancos e descendentes de escravocratas, mantém um sistema de privilégios e riquezas que resulta da exploração do trabalho de negras e negros e do seu sistemático não acesso a políticas e recursos". (Relatório, 2018, p. 19).
}

O recorte temporal do Relatório 2018 está compreendido entre os anos de 2008 a 2017, abrange as cinco regiões do Brasil e está organizado em seis capítulos. No primeiro capítulo o Relatório 2018 traça uma análise histórica e conjuntural sobre a dimensão das questões quilombolas no Brasil, sob o título, "O quilombo fala: Enegrecer o debate sobre violência estrutural e políticas públicas nos territórios quilombolas". No segundo capítulo, "Mapeando a violência contra quilombos no Brasil" é apresentado um mapeamento das violências enfrentada pelos quilombos no Brasil.

No terceiro capítulo, "Avanços e retrocessos na política pública de titulação dos territórios quilombolas", o relatório constata o racismo institucional diante da ineficácia do Estado brasileiro em titular os territórios quilombolas. No quarto capítulo, "Violência e retrocesso na luta por direitos quilombolas na Bahia", a AATR apresenta a situação especifica do estado da Bahia que conta com 736 quilombos reconhecidos pela Fundação Cultural Palmares (FCP), ou seja, com certidões expedidas e procedimentos abertos para fins de titulação pelo Instituto de Colonização e Reforma Agrária (INCRA), conforme determina o Decreto n 4.887, de 20 de novembro de 2003.

O estudo de caso centrado no Estado da Bahia demonstra que é nessa região do Brasil (Nordeste) que entre os anos de 2016 e 2017 o número de homicídios contra quilombolas aumentou de forma drástica, visto que foram reportados os assassinatos de 11 quilombolas apenas na Bahia.

No capítulo cinco, “A importância da assessoria popular como estratégia de lutas para as comunidades quilombolas”, Carlos Frederico Marés de Souza Filho apresenta a formação da AJUP no Brasil e atuação de grupos em defesa dos direitos humanos a partir de uma perspectiva contrahegemônica e coletiva, ou seja, das medicações entre o político e o jurídico em uma 
compreensão ampliada de mobilização por direitos. O destaque é a consolidação do Coletivo de Assessoria Jurídica Popular Joãozinho do Mangal, em 2016.

Por fim, o capítulo seis, "Mulheres da CONAQ: organização e luta pela vida das mulheres quilombolas", é apresentado pelo Coletivo de Mulheres da CONAQ criado em 2015 e que atua em consonância com as pautas antirracistas dos movimentos negros, do combate às violências impostas aos corpos das mulheres, em uma dimensão individual e/ou coletiva,

\begin{abstract}
"Os assassinatos de mulheres quilombolas ocorreram nos anos de 2008, 2013, 2015, 2016 e 2017. O número de ocorrências de assassinatos de mulheres no período mencionado coloca em discussão os seguintes elementos: (1) as violências contra mulheres são invisibilizadas com subnotificação dos casos de assassinatos de lideranças quilombolas mulheres; (2) muitos casos são considerados como feminicídios comuns e não decorrentes da luta pelo território e/ou defesa dos direitos humanos; (3) a exposição das mulheres a maior risco registra-se, sobretudo nos últimos anos, quando passaram a assumir papéis de liderança pública". (Relatório, p. 54)
\end{abstract}

O Relatório, ao resgatar a autora Beatriz Nascimento, presta um reconhecimento a uma das intelectuais negras brasileira que colaboraram para uma outra abordagem sobre a questão racial no Brasil. Ela e Abdias Nascimento propuseram que as principais ressignificações das análises históricas e sociológicas sobre o processo de escravidão constituíram percepções que fossem narradas a partir da rebeldia dos quilombo, ao invés da repetição de jargões sobre uma ideia de resignação da população negra diante dos desafios, a tentativa política e científica de retratar uma sociedade e o Estado brasileiros sob os auspícios da democracia racial, assim como a ruptura com relatos que apenas manifestassem as violências (torturas, estupros e outras) e submissão das(os) negros. O giro epistêmico se constitui como aglutinador de outras memórias e de autoestima da população negra brasileira.

\title{
CONSIDERAÇÕES FINAIS:
}

A mobilização por direitos humanos a partir da realidade social, política, cultural e econômica dos quilombos não é novidade no Brasil. O Boletim Informativo NUER, em 1997, inicia uma série de estudos sobre identidade e relações interétnicas.

A Procuradora da República do Ministério Público Federal do Brasil Deborah Duprat (2007), a partir de sua atuação em defesa das comunidades quilombolas, condensou os principais contributos políticos-jurídicos de quase duas décadas após a Constituição Federal da República do Brasil (1988) para constituir um arco de defesa argumentativa contra os avanços de legislações no Congresso Nacional Brasileiro contra os direitos humanos. Na obra Pareceres Jurídicos - Direito 
dos Povos e das Comunidades Tradicionais o conceito trabalhado é o direto pluriétnico e multicultural (2007), a defesa da posse, do processo de desapropriação, das formas de titulação e delimitação dos territórios são apresentados com o intuito de aproximar o sistema de justiça da temática quilombola.

A produção de materiais, como o Relatório Racismo e Violência contra Quilombos no Brasil, é que, nas elaborações dos relatórios de violações de direitos humanos, nas formas de resistência, na promoção, na defesa destes direitos, assim como nas atividades de mapeamento territorial, nos censos demográficos e nas cartografias sociais (Acselrad 2013), se fazem perceptíveis os indicadores de políticas públicas com a finalidade de estabelecer mudanças (permanências) sociais, políticas, econômicas e culturais.

Nesse mesmo sentido, a assessoria jurídica popular trabalha em diversas frentes de produção. Por exemplo, além dos relatórios, petições e denúncias, buscou-se através da técnica jurídica reforçar sua posição junto ao Supremo Tribunal Federal do Brasil em face do julgamento da Ação Direita de Constitucionalidade no 3239, produzindo, em 2015, a obra Direito Constitucional Quilombola, organizada por Fernando Prioste e Eduardo Araújo (2015).

As constantes denúncias de violações de direitos humanos das(os) quilombolas por parte dos empreendimentos do capitalismo (mineração, monocultura e exploração de bens naturais), naturalização do racismo (institucional) e a ação (omissão) dos Estados em fatos denunciados perante o Sistema de Justiça (interno e internacional), demonstram que o período de defesa desses direitos de reconhecimento dos atores sociais precisam estar articulados com outras experiências, mesmo que incompletas, mas que tenham um impacto global-local.

O racismo, o classismo, o patriarcado-machismo, o imperialismo e o (neo)coloniaslimo fazem parte de uma ideologia assentada no capitalismo (neoliberalismo) que atravessa as democracias atacando suas instituições e fragilizando os grupos subalternizados, conforme aponta as autoras do Relatório,

\footnotetext{
" Gênero, raça e classe, para ficar com ao menos três marcadores sociais importantes, estruturam as relações socioespaciais no Brasil. O processo de criminalização, ataques, ameaças, atos violentos e assassinatos presente nos quilombos possui relação direta com sua defesa e com a garantia de permanência no território. Defender seu espaço e seu modo de vida são ações historicamente negadas às e aos quilombolas, dentre outras razões, pela estrutura fundiária existente no país, consolidada ao longo da exclusão racista no acesso à terra e pela ausência de reparação ao povo negro pelos mais de 300 anos de escravidão". (Relatório, 2018, p.30)
}

Neste sentido, se a materialização da liberdade surge em contextos de conflitos por justiça social através dos enfretamentos às violências coloniais, nas lutas por dignidade e da afirmação histórica de direitos (Davis, 1981, 2018; Fanon, 1975, 2015; Porto-Gonçalves, 2016), na questão 
quilombola, o combate permanente contra o racismo é que proporciona mudanças de paradigmas na sociedade brasileira. Os conflitos também visto enquanto constitutivos da política revelam (alteram) os dados socioeconômicos e normativos, ampliam valores culturais e dinamizam mobilizações por direitos humanos, por isso, o Relatório constituí uma narrativa, feita por histórias e memórias individuais e/ou coletivas que reclamam o direito a futuros.

Por fim, se são as análises históricas, antropológicas e políticas (acadêmicas) sobre os quilombos que apontam para estes enquanto mobilizadores ou sujeitos coletivos de direitos humanos, é na ancestralidade que estão as "memórias bioculturais" (Toledo, 2015) que transcendem categorias analíticas e espaço-tempo.

O que está dado no presente, pelo quilombos e suas assessorias são sabares-fazeres da fusão do real com o utópico em uma conjuntura global-local dos direitos humanos na qual o encantamento pelo mundo parece esmorecer, o Relatório aponta para o protagonismo das mulheres quilombolas em suas lutas diárias, a partir das suas histórias (orais e escritas) e nos processos (re)existências que produzem lugares e outras fronteiras de confronto aos racismos contribuindo para expansão teórica e prática da mobilização por direitos humanos(Santos, 2007). As mulheres quilombolas ao estremecer as zonas de conforto do pacto da branquitude brasileira fazem como Zumbi e Dandara, projetam atravessar mais um século aterrorizando a Casa Grande, visto que, ninguém voltará para Senzala.

\section{REFERÊNCIAS:}

ACSELRAD, Henri. 2013. Apresentação - Cartografia social, terra e território In: ACSELRAD, Henri (Org). Cartografia social, terra e território. Rio de Janeiro: Universidade Federal do Rio de Janeiro, Instituto de Pesquisa e Planejamento Urbano e Regional, [Coleção território, meio ambiente e conflitos sociais]. p. 05-14.

ALMEIDA, Alfredo Wagner Berno. 2002. O quilombo e as novas etnias. In: O'DWYER, Eliane Cantarino. Quilombos: identidade étnica e territorialidade. Rio de Janeiro: Ed. FGV/ABA. p. 43-82.

ARRUTI, José Maurício. 2006. Mocambo: Antropologia e história do processo de formação quilombola.1. ed. Bauru: Edusc.

Boletim Informativo NUER1.1997. Núcleo de Estudos sobre Identidade eRelações Interétnicas / Fundação Cultural Palmares - v. 1, n. L 2 ed.- Florianópolis: UFSC.

BRASIL. Decreto $n^{\circ} 4.887$, de 20 de novembro de 2003 - Regulamenta o procedimento para identificação, reconhecimento, delimitação, demarcação e titulação das terras ocupadas por remanescentes das comunidades dos quilombos de que trata o art. 68 do Ato das Disposições Constitucionais Transitórias.

DAVIS, Angela. 1981. Women, Race \& Class. New York: Vintage books. 
DAVIS, Angela. 2018. A liberdade é uma luta constante. Frank Barat (Org.); [Tradução Heci Regina Candiani]. 1.ed. São Paulo: Boitempo.

DUPRAT, Deborah (Org.). 2007. Pareceres Jurídicos - Direito dos Povos e das Comunidades Tradicionais Manaus: uea.

FANON, Frantz. 1975. Pele Negra Máscaras Brancas. Porto: Paisagem

FANON, Frantz. 2015. Os condenados da terra. Lisboa. Livraria Letra Livre.

FREITAS, Décio .1982. Cabanos: os Guerrilheiros do Imperador. 2.ed. Rio de Janeiro: Graal.

GOMES, Flávio. 2005. Palmares: Escravidão e liberdade no Atlântico Sul. São Paulo: Contexto.

LOPES, Nei. 1998. Bantos, Malês e Identidade Negra. Rio de Janeiro: Forense Universitária.

NASCIMENTO, Abdias. 2002. O quilombismo.2 ed. OR Editor Produtor Editor. Fundação Palmares, Brasília / Rio de Janeiro.

PRIOSTE; ARAÚJO, Fernando; Eduardo (Orgs.). 2015. Direito Constitucional Quilombola. Rio de Janeiro: Lumen Juris.

PORTO-GONÇALVES, Carlos Walter (org.). 2016. Despojos y resistências en América Latina, AbyaYala / Buenos Aires: Estudios Sociológicos Editora.

Relatório Racismo e Violência contra Quilombos no Brasil. 2018. Brasília. Coordenação Nacional de Articulação das Comunidades Negras Rurais Quilombolas e Terra de Direitos.

RIBEIRO, Darcy. 1995. O povo brasileiro - A formação e o sentido do Brasil. São Paulo: Companhia das Letras.

SANTOS, Cecília MacDowell. 2007.Transnational Legal activism and the State: reflections on cases against Brazil in the Inter-American Commission on Human Rights. Sur - International Journal of Human Rights. pp.29-59.

TOLEDO, Víctor. 2015. A memória biocultural: a importância das sabedorias tradicionais. Víctor M. Toledo; Narciso Barrera - Bassols; [Tradução [de] Rosa L. Peralta]. São Paulo: Expressão Popular. 


\section{AUTORES:}

\section{Eduardo F. de Araújo}

Professor da Universidade Federal da Paraíba (UFPB), no Departamento de Ciências Jurídicas Santa Rita. Bacharel em Direito. Especialista em Direitos Humanos. Mestre em Ciências Jurídicas. Doutorando na Universidade de Coimbra (Doutorando no Centro de Estudos Sociais). Integrante do Núcleo de Estudos e Pesquisas Afro-brasileiros da UFPB. Integrante do Coletivo Joãozinho do Mangal - Assessoria Jurídica Popular - da Coordenação Nacional das Comunidades Negras Rurais Quilombolas - (CONAQ). Associado da Associação Brasileira de Pesquisadoras(es) Negras (os) (ABPN).

E-mail: eduardo.f.ojuara@gmail.com

\section{Givânia Maria da Silva}

Educadora e quilombola. Graduada em Letras e especialista em Programação de Ensino e Desenvolvimento Local Sustentável. Mestra em Políticas Públicas e Gestão da Educação pela Universidade de Brasília (UnB). Doutoranda no Programa de Pós-Graduação em Sociologia da UnB. Integrante do Núcleo de Estudos Afro-brasileiros e do Grupo de Estudo Mulheres Negras ambos da UnB. Bolsista do CNPq. Fundadora CONAQ. Associada e integrante do Conselho Fiscal da ABPN. Autora do livro Educação e Luta do Quilombo de Conceição das Crioulas, Ed. Appris, 2016.

E-mail: givaniaconceicao@gmail.com 